\title{
Characterization of a Bacteriophage Virulent for Streptomyces coelicolor A3(2)
}

\author{
By J. E. DOWDING* \\ John Innes Institute, Colney Lane, Norwich NOR $70 \mathrm{~F}$
}

(Received 13 December I972)

\begin{abstract}
SUMMAR Y
The isolation of a group of phages attacking the actinomycete Streptomyces coelicolor A3(2) is described. One of the phages, VP I I, has been characterized, with emphasis on the ways in which it might aid studies on the host organism. VP I I is a virulent DNA phage with a wide host range. It has a latent period of $40 \mathrm{~min}$ at $30^{\circ} \mathrm{C}$ and an average burst size of about 40 . The phage has been examined electron-microscopically and found to belong in group B of Bradley's morphological classification. It has also been shown to be host-cell reactivated after u.v.-irradiation. Two temperature-sensitive mutations have been shown to undergo recombination. The phage requires $\mathrm{Ca}^{2+}$ for stability and is very sensitive to chelating agents. Some of the difficulties encountered in using a mycelial organism as a host in phage studies are described and discussed.
\end{abstract}

\section{INTRODUCTION}

Bacteriophages attacking actinomycetes are commonly known as actinophages. Since they were first isolated by Wieringa \& Wiebols (I936), many such phages have been reported, particularly for members of the genus Streptomyces; a comprehensive review of this literature is given by Welsch (I969). There have, however, been few studies on phages attacking Streptomyces coelicolor A3(2). An unsuccessful attempt to isolate such phages from natural substrates by a variety of methods was described by Collard (1970) and, more recently, a number of reports have been published on the induction and mapping of a prophage carried by the strain (Lomovskaya, Emeljanova \& Alikhanian, 197I) and the characterization of the phage ØС 3I (Lomovskaya, Mkrtumian, Gostimskaya \& Danilenko, 1972).

The main purpose of the work reported here was to introduce and, where necessary, adapt classical phage methods to the study of Streptomyces coelicolor A3(2). Considering the detail in which it has been studied genetically (Hopwood, 1967), this strain is clearly the streptomycete in which most is to be gained from studies with phages. Phages may well prove to be useful tools in the study of the complex morphogenetic (Chater \& Hopwood, 1973) and fertility (Vivian, I97I) systems. They may also permit the recognition of other phenomena (such as host-controlled modification and restriction and various suppressor systems) that were first recognized in eubacteria by the use of phages. The lack of a suitable bacteriophage to aid analysis of ultraviolet-sensitive mutants has already been noted (Harold \& Hopwood, I970a).

* Present address: Department of Biochemistry, University of Wisconsin, Madison, Wisconsin 53706, U.S.A. 


\section{METHODS}

General bacterial techniques. Unless otherwise stated, the organism used in this study was Streptomyces coelicolor A3(2) (S. violaceoruber according to Kutzner \& Waksman, I959). The origin of this strain has been described by Hopwood \& Sermonti (1962). Composition of media for $S$. coelicolor and general host techniques, including maintenance and propagation of stocks, preparation of spore suspensions and mapping procedures were described by Hopwood \& Sermonti (1962) and Hopwood (1967).

Media. Nutrient broth was Difco Bacto-Nutrient Broth. Nutrient agar and soft agar were nutrient broth solidified by the addition of 15 and $5 \mathrm{~g}$ respectively of Oxoid no. 3 Agar/l before autoclaving. Nutrient broth and nutrient agar were supplemented after autoclaving with a sterile glucose solution to a final concentration of $0.5 \%$ and a sterile solution of $\mathrm{Ca}\left(\mathrm{NO}_{3}\right)_{2} \cdot 4 \mathrm{H}_{2} \mathrm{O}$ to a final concentration of $4 \mathrm{~mm}$.

General phage techniques. Phage assay was by the conventional double-layer technique. Soft agar, maintained at 46 to $47^{\circ} \mathrm{C}$, was inoculated with a dense spore suspension until the mixture was faintly turbid (this corresponds to a density of approximately $10^{7}$ colony-forming units (c.f.u.)/ml). Preliminary experiments demonstrated that pregermination of spores gave no measurable increase in phage efficiency of plating (e.o.p.). Phage lysates were diluted in nutrient broth, $0 . \mathrm{I} \mathrm{ml} \mathrm{samples} \mathrm{were} \mathrm{pipetted} \mathrm{on} \mathrm{to} 25 \mathrm{ml}$ nutrient agar base layers and each plate was immediately overlaid with $2.5 \mathrm{ml}$ of the soft agar/host mixture. Plates were incubated at $30^{\circ} \mathrm{C}$ overnight.

Phage lysates were sterilized by membrane filtering through 13 or $25 \mathrm{~mm}$ Millipore filters of pore size $0.45 \mu \mathrm{m}$ in Swinnex Filter Units (Millipore Corporation, Bedford, Massachusetts, U.S.A.).

Phage isolation and purification. Soil samples were assayed either by the method of Welsch, Minon \& Schönfeld (I955), involving the direct testing of a sterilized liquid extract of the soil on potential hosts, or by specific enrichment. In the latter technique, 10 to $20 \mathrm{~g}$ of soil were incubated overnight at $30^{\circ} \mathrm{C}$ with shaking in $20 \mathrm{ml}$ of nutrient broth inoculated with a spore suspension of $\mathrm{A3}(2)$ to a final concentration of $10^{6}$ to $10^{7} \mathrm{c} . \mathrm{f} . \mathrm{u} . / \mathrm{ml}$. The mixture was centrifuged at low speed and a sample of the supernatant was membrane filtered, diluted and plated on $\mathrm{A} 3(2)$.

Where plaques appeared in the bacterial lawn they were isolated by picking to a small vol. of broth. Only one plaque was picked from each enrichment and each phage strain was purified by picking three times from a well-isolated single plaque before a lysate was prepared.

Lysates. Lysates of VP I I were prepared in two ways. Confluent-plate lysates were prepared by plating $1 \mathrm{I}^{4}$ to $1 \mathrm{I}^{5}$ p.f.u./plate and incubating overnight. Plates were extracted by soaking at room temperature for $\mathrm{I} \cdot 5$ to $2 \mathrm{~h}$ with about $5 \mathrm{ml}$ of nutrient broth. Such lysates normally contained approx. $10^{8}$ p.f.u. $/ \mathrm{ml}$. Shaking-flask lysates were prepared by inoculating $20 \mathrm{ml}$ of nutrient broth in a $250 \mathrm{ml}$ conical flask with a spore suspension of A3(2) (final concentration $10^{7}$ to $10^{8}$ c.f.u. $/ \mathrm{ml}$ ) and a phage suspension to give a concentration of about $10^{7}$ p.f.u./ $\mathrm{ml}$. The flask was incubated overnight at $30^{\circ} \mathrm{C}$ with vigorous shaking. Such lysates normally contained 2 to $4 \times 10^{9}$ p.f.u. $/ \mathrm{ml}$.

Concentration and purification of lysates. Concentration and partial purification of lysates was achieved by two cycles of differential centrifugation. Large cellular debris was removed by a low-speed spin and membrane filtration. Phages were pelleted by spinning for $90 \mathrm{~min}$ in a Spinco L I-50 (Type 30 rotor) at $20000 \mathrm{rev} . / \mathrm{min}\left(r_{\mathrm{av} .}=34900 \mathrm{~g}\right)$. Pellets were gently resuspended in $0.1 \mathrm{M}$-ammonium acetate solution and the procedure was repeated. The final pellet was suspended in $0.0 \mathrm{I} \mathrm{M}$-ammonium acetate for electron-microscope examination. 
Preparation of hyphal ghosts. A $20 \mathrm{ml}$ sample of nutrient broth in a $250 \mathrm{ml}$ flask was inoculated with a spore suspension of $\mathrm{A} 3(2)$ and incubated overnight at $30^{\circ} \mathrm{C}$ with shaking. The resulting mycelium was washed, suspended in $25 \mathrm{ml}$ of distilled water and sonicated for five I-min bursts with a Dawe 'Soniprobe' Type 7530 A with 'Micro-Tip' attachment (Dawe Instruments Ltd, London) operated at output level 4 . Unbroken cells and large ghosts were removed by centrifuging at $2000 \mathrm{~g}$ for $\mathrm{I} \mathrm{min}$. The turbid supernatant was respun at $6000 \mathrm{~g}$ for $2 \mathrm{~min}$. The pellet obtained consisted almost entirely of ghost hyphae. Phage particles were adsorbed to the hyphae by resuspending this pellet in approximately $5 \mathrm{ml}$ of a crude lysate (about $10^{9}$ p.f.u. $/ \mathrm{ml}$ ) and allowing the mixture to stand overnight at $4{ }^{\circ} \mathrm{C}$. The phage/host complexes were collected by low-speed centrifugation, washed in distilled water and resuspended in about $\mathrm{I} \mathrm{ml}$ of water for examination.

Preparation and examination of specimens. Phosphotungstic acid 'AnalaR' (Taab Laboratories, Reading, Berkshire) was made up to $2 \%$ in distilled water and brought to $\mathrm{pH} 7.0$ with $\mathrm{KOH}$. Droplets of phage suspension and negative stain were mixed on carbon- or carbon-Formvar-coated grids $(2 \cdot 3$ or $3.0 \mathrm{~mm})$, the excess liquid was blotted with filter paper and the grids were allowed to air-dry. Grids were examined in either a Siemens Elmiskop I A operated at an accelerating voltage of $80 \mathrm{kV}$ or an AEI EM $6 \mathrm{~B}$ at $60 \mathrm{kV}$. Exposures were made on Ilford Type EM-5 plates.

Adsorption. Adsorption rates were determined by measuring residual plaque-forming ability in membrane-filtered samples of an attachment mixture. A $250 \mathrm{ml}$ conical flask containing $50 \mathrm{ml}$ of nutrient broth was inoculated with a host suspension and the final concentration was determined by reference to a calibration curve of $E_{620}$ against c.f.u./ml. The host was incubated with shaking at $30^{\circ} \mathrm{C}$ for 5 to $6 \mathrm{~h}$ to allow spore germination to occur. Phage was added at low multiplicity (usually $\mathrm{IO}^{-2}$ to $\mathrm{IO}^{-3}$ ) and the incubation was continued. At various times samples were removed, membrane-filtered, diluted and plated.

One-step growth experiment. A spore suspension of A3(2) of initial concentration $6 \times 10^{7}$ c.f.u. $/ \mathrm{ml}$ was incubated in broth for $5 \mathrm{~h}$ to allow spore germination. A predetermined quantity of VP I I was added to give a low multiplicity (approximately $O^{\circ}$ I) and the incubation was continued for $20 \mathrm{~min}$. A $10 \mathrm{ml}$ sample of the attachment mixture was removed and membrane-filtered. Unadsorbed phages were removed from the infected centres on the filter by passing $\mathrm{I} 0 \mathrm{ml}$ of broth through the filter to wash them. The filter was transferred to a flask containing $50 \mathrm{ml}$ of broth at $30^{\circ} \mathrm{C}$ (first growth flask) and the infected centres were resuspended by agitating the flask. A 50 -fold dilution was made to another flask held at $30{ }^{\circ} \mathrm{C}$ (second growth flask) and the two flasks were reincubated at $30^{\circ} \mathrm{C}$. Samples $(0 \cdot 1 \mathrm{ml})$ were removed (from the first growth flask until time $35 \mathrm{~min}$ and then alternately from the two flasks) and plated immediately. Plaques formed by infected centres were much larger than those from free phages; this difference was used to show that the washing procedure on filters was more than $99 \%$ effective in removing free phages from the infected centres since early samples from the first growth flask yielded very few free phage plaques.

Phage mutagenesis. I-Methyl-3-nitro-I-nitrosoguanidine (NG) was from Aldrich Chemical Co., Milwaukee, Wisconsin, U.S.A. NG mutagenesis was performed essentially according to the method described by Studier (1969). A spore suspension of A3(2) was germinated in broth and NG was added to a final concentration of $20 \mu \mathrm{g} / \mathrm{ml}$. Phage was added to an approximate multiplicity of $O \cdot I$ and the incubation was continued for 60 to $70 \mathrm{~min}$ to allow lysis to occur. The contents of the flask were membrane-filtered, diluted and plated.

Phage crosses. Crosses were performed according to the basic principles outlined by Edgar (1963), modified as follows. A spore suspension of $\mathrm{A}_{3}(2)$ was germinated in broth after its initial concentration had been determined by $E_{620}$ and by plating. A solution of $\mathrm{NaCN}$ was 

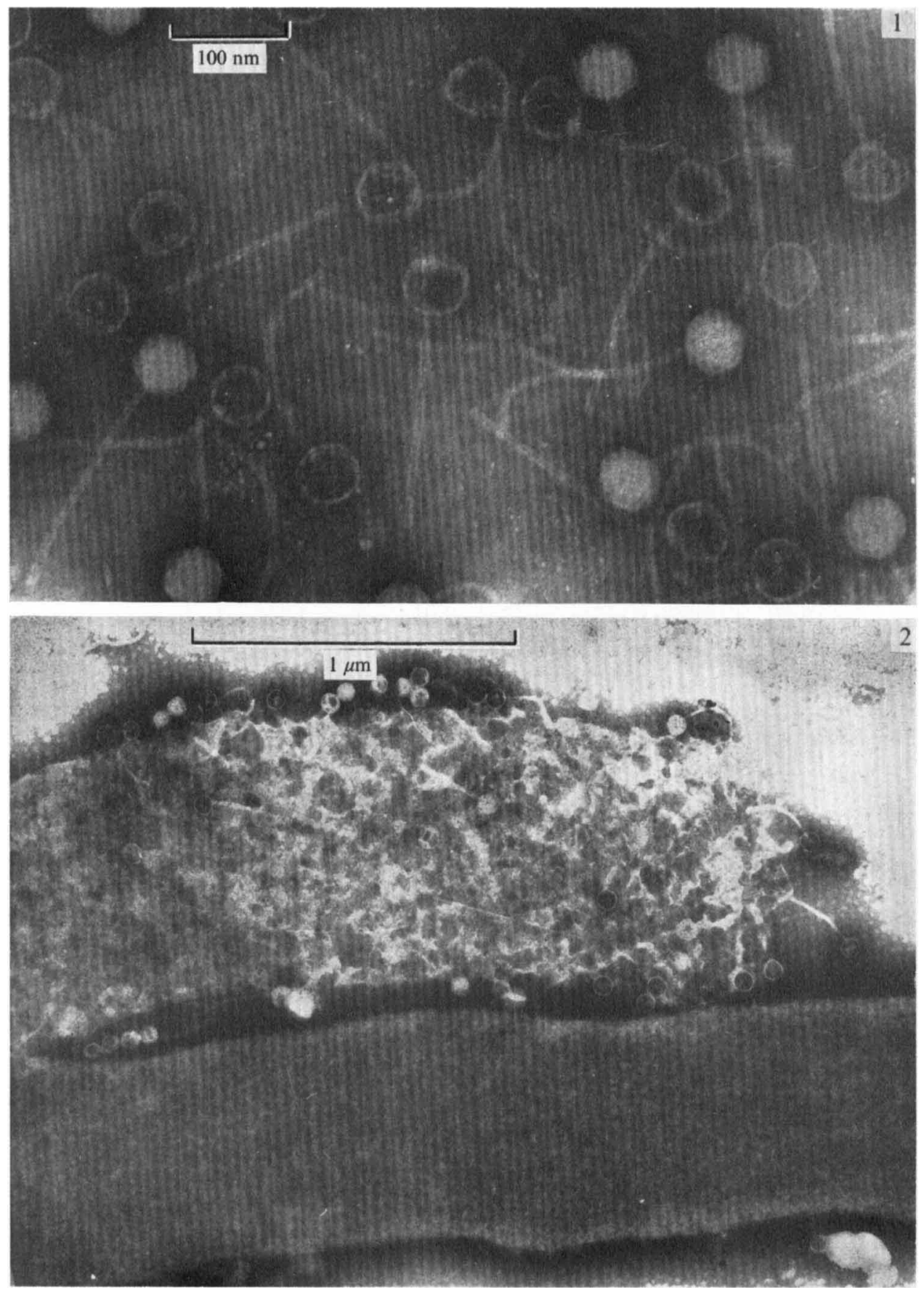

Fig. I. Electron micrograph of a purified preparation of VP II negatively stained with potassium phosphotungstate.

Fig. 2. Electron micrograph showing VP I I particles adsorbed to hyphal 'ghosts', negatively stained with potassium phosphotungstate. Both smooth and mottled hyphae are shown, with phage adsorbed only to the latter. 


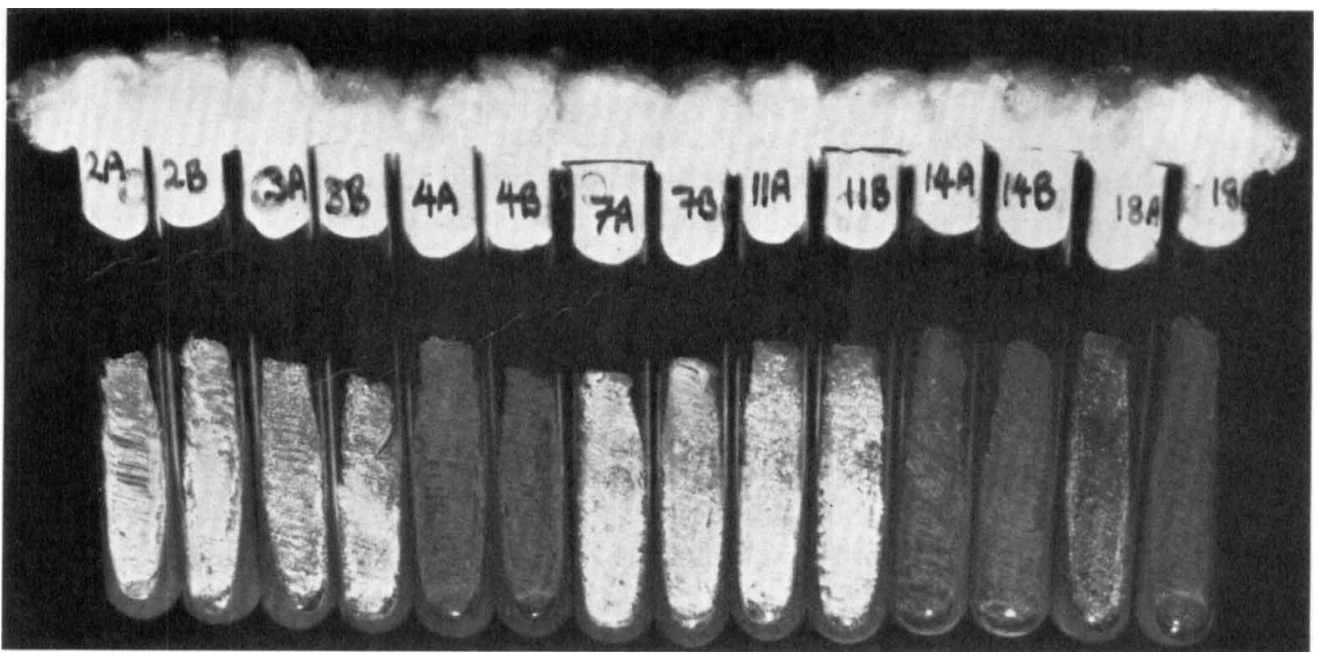

Fig. 3. Appearance of Streptomyces glaucescens ETH24204 grown on minimal medium. Tube numbers signify culture age in days.

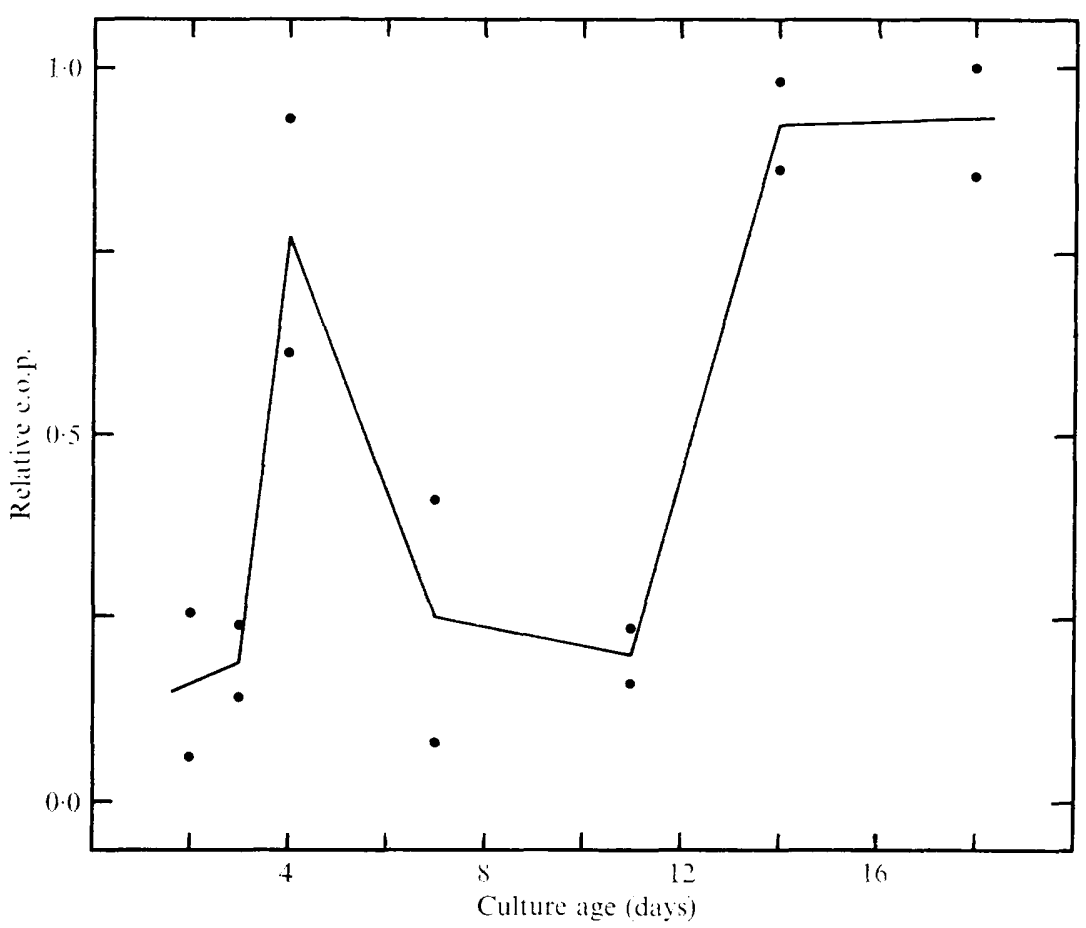

Fig. 4. Relative efficiencies of plating of a VP I I lysate on the cultures shown in Fig. 3.

added to give a concentration of $2 \mathrm{~mm}$ and phage was added to give the desired multiplicity of each strain in a total volume of $20 \mathrm{ml}$. The mixture was incubated for $60 \mathrm{~min}$ to allow attachment of the majority of the phages (usually 95 to $99 \%$ ). A $5 \mathrm{ml}$ sample of the mixture was then membrane-filtered and the filtrate retained to determine the proportion of unattached phage. The infected centres were washed by passing $10 \mathrm{ml}$ of broth through the filter 
and were then resuspended in $20 \mathrm{ml}$ of broth in a $250 \mathrm{ml}$ flask. A sample was plated immediately and incubated at $28{ }^{\circ} \mathrm{C}$ to determine the concentration of infected centres. The flask was incubated at $28{ }^{\circ} \mathrm{C}$ for $60 \mathrm{~min}$ (visible lysis occurred after 40 to $50 \mathrm{~min}$ ) and a sample was membrane-filtered, diluted, plated and incubated at 28 and $36{ }^{\circ} \mathrm{C}$.

U.v. irradiation. Lysates were diluted I0o-fold in distilled water and $3 \mathrm{ml}$ samples were irradiated, with stirring, in $5 \mathrm{~cm}$ dishes for various times at a distance of $29 \mathrm{~cm}$ from a masked Philips $30 \mathrm{~W}$ IXTUV lamp. The dose rate of this lamp under these conditions, measured with a Blak-Ray Ultra-violet Intensity Meter (Ultra-Violet Products Inc., San Gabriel, California, U.S.A.), was $12 \mathrm{ergs} / \mathrm{mm}^{2} / \mathrm{s}$. Samples were diluted and plated on various $u v s$ and $u v s^{+}$hosts.

\section{RESULTS}

Isolation and host range of VP I I. Each of 52 soil samples was assayed either by the direct method of Welsch et al. (1955) or by specific enrichment. Both techniques proved successful although relatively few samples ( 3 out of 24 ) yielded phages by the direct method. Specific enrichment, on the other hand, proved very efficient. Twenty-five out of 28 samples tested by this technique yielded phages. One isolate (VP I I), which had large clear plaques, was chosen for further study.

The host range of VP I I was determined by testing the phage for its ability to produce single plaques on lawns of potential hosts. VP I I was found to have a very wide host range, attacking 21 of 23 mesophilic streptomycetes tested. It did not attack Thermoactinomyces vulgaris CUB 76, a strain of Nocardia mediterranei or three thermophilic Streptomyces spp. tested.

Electron-microscopic examination. A field of VP I I particles from a purified preparation is shown in Fig. I. Full and empty particles and separated heads and tails are visible. VP I I has a long, flexible, non-contractile tail and thus belongs in group B of Bradley's morphological classification of bacteriophages (Bradley, I967).

Measurements were taken directly from the plates and values quoted are averages from 20 particles. VP I I was found to have a hexagonal head of length $55.5 \pm 2.6 \mathrm{~nm}$ and width $55 \cdot 0 \pm \mathrm{I} \cdot 5 \mathrm{~nm}$ and a tail $220 \pm 9 \mathrm{~nm}$ in length. Tail width was more difficult to measure accurately but was between IO and I $2 \mathrm{~nm}$. The spacing of the tail striations, determined by measurements taken from a microdensitometer tracing made on a negative taken at a magnification of 106000 , was found to be $4 \cdot 5 \pm 0.5 \mathrm{~nm}$.

First attempts to visualize VP I I particles attached to host hyphae were unsuccessful because the contents of the cells took up much of the negative stain. This had the effect of obscuring the areas directly surrounding the cells where phage particles would normally be seen. Hyphal ghosts were therefore prepared and phages attached to them as described above.

Fig. 2 shows particles of VP I I adsorbed to a fragment of mycelium. In this and other preparations, two types of mycelium were observed. One of these had a smooth, homogeneous appearance and did not adsorb VP I I while the other was rough and heterogeneous and did adsorb the phage. The nature of the difference between the two types of mycelium was not discovered. It did not appear to be due to sonication damage and was not a difference of age.

Influence of host culture age on VP I I plating efficiency. Two strains, Streptomyces glaucescens ETH24204 and $S$. coelicolor A3(2), were used in experiments to determine the effect of the stage of development of the host on phage e.o.p. On solid media both strains go through the developmental cycle of spore germination, substrate mycelium, aerial mycelium and sporulation described by Hopwood, Wildermuth \& Palmer (I970). 
Table I. Efficiency of plating of VP I I on some morphological mutants of Streptomyces coelicolor A3(2)

Results are averages from triplicate plates showing between 50 and 300 plaques

\begin{tabular}{llll} 
Host strain & \multicolumn{3}{c}{ Relative e.o.p. of VP I I } \\
A3(2) & 1.00 & I.00 & 0.94 \\
whiA13 & 0.57 & 0.65 & 0.32 \\
whil46 & 0.57 & 0.48 & 0.43 \\
bldAI & 0.64 & 0.81 & 0.18
\end{tabular}

Streptomyces glaucescens ETH24204 grown on complete medium produced substrate mycelium until 8 to 9 days old. After this, aerial mycelium production and sporulation occurred rapidly. By plating a VP I I lysate on cultures of different ages it was found that phage plating efficiency on substrate mycelium was approximately I000-fold lower than on cultures consisting mainly of spores.

Fig. 3 shows Streptomyces glaucescens ETH24204 grown on minimal medium. Under these conditions, little substrate mycelium is produced. Abundant white aerial mycelium can be seen after 2 to 3 days and sporulation occurs at 4 days, giving the cultures a green colour (dark in Fig. 3). Many of the spores present then germinate to give secondary aerial growth ( 7 to I I days) and this in turn sporulates (I 4 to I 8 days). Fig. 4 shows the result of plating a VP I I lysate on each of the cultures shown in Fig. 3. The two peaks of phage e.o.p. coincide with sporulating host cultures.

In the case of $\mathrm{A} 3(2)$, stages in differentiation can be conveniently separated by the use of morphological mutants (Hopwood et al. 1970). Mutants blocked in the formation of aerial mycelium, i.e. producing only substrate mycelium, are designated 'bald'; strain II68 (bldAI) is used to represent this group. Mutants which are able to form aerial mycelium but are defective in the production or spacing of sporulation septa have a white colony phenotype designated whi. Two members of this group, whil46 and whiAI3, were chosen for study. The two mutations map at different loci and result in quite different phenotypes (Hopwood et al. 1970; Chater, 1972). Suspensions of each mutant and of wild-type A3(2) were prepared in triplicate and used to determine the relative e.o.p. of a VP I I lysate (Table I).

Results with both strains show that spore suspensions consistently gave the highest phage e.o.p. although differences between the various developmental stages (except on Streptomyces glaucescens substrate mycelium) were relatively small.

Adsorption. Adsorption rates were determined using both spores, from A3(2), and mycelium, from strain I 168.

Control experiments showed that shaking at $30^{\circ} \mathrm{C}$ without host present resulted in falls in phage titres of $5 \%$ or less after $30 \mathrm{~min}$ of incubation. Experiments using ungerminated spores in the attachment mixture gave very similar results - recovery of phage was always better than $90 \%$ after $20 \mathrm{~min}$. These adsorption values were considered insignificant compared with those obtained in experiments using germinated spores and mycelium.

Plots of the percentage of unadsorbed phage against time on semilog. paper were linear between $O$ and $35 \mathrm{~min}$ for germinated spores and mycelium. At $40 \mathrm{~min}$ adsorption rates appeared to fall. Counts from samples taken after 40 min increased, sharply in the case of germinated spores, suggesting that infected cells were lysing and liberating phages. Adsorption rate constants were determined (Adams, 1959) and gave a range of values between $5.3 \times 10^{-10}$ and $1 \cdot 2 \times 10^{-9} \mathrm{ml} \mathrm{min}-1$ for germinated spores and between $\mathrm{I} \cdot 2 \times 10^{-9}$ and $2 \cdot 8 \times$ $10^{-9} \mathrm{ml} \mathrm{min}-1$ for mycelium. The validity of these values will be considered in the Discussion. 


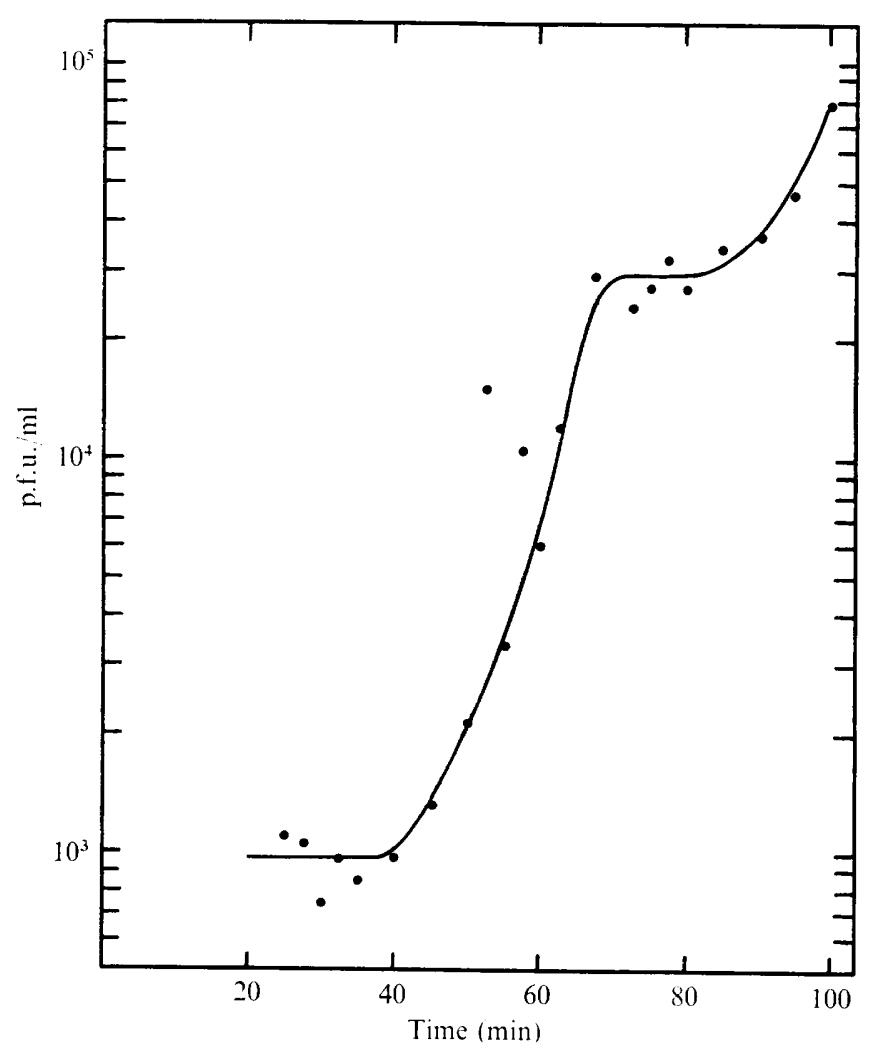

Fig. 5. One-step growth curve of VP I I on Streptomyces coelicolor A3(2) at $30{ }^{\circ} \mathrm{C}$.

One-step growth experiment. The one-step growth curve of VP II is shown in Fig. 5. As pointed out by Adams (1959), an infected centre from the second growth flask may lyse during the time the sample is being plated and may thus give an artificially high count. For this reason, the curve is drawn through the lowest set of points during the rise period.

The curve gives a value of $40 \mathrm{~min}$ for the minimum latent period, confirming the observation made during adsorption experiments. The rise period of $30 \mathrm{~min}$ is composed of the $20 \mathrm{~min}$ allowed for attachment and a $\mathrm{I} 0 \mathrm{~min}$ natural variation in burst time. The average burst size is between 30 and 35. Factors which may have influenced these values (particularly the average burst size) will be considered in the Discussion. Fig. 5 also shows that there is sufficient uninfected host present for some of the phages released to attach to it and begin a second growth cycle. The second burst begins at about $80 \mathrm{~min}, 40 \mathrm{~min}$ after the first burst has begun. This again confirms the value of $40 \mathrm{~min}$ for the minimum latent period.

Role of $\mathrm{Ca}^{2+}$. Divalent cations, particularly $\mathrm{Ca}^{2+}$, have long been known to enhance phage stability and/or act as adsorption co-factors. As might be expected, chelating agents often decrease phage stability or prevent adsorption. These wide-ranging effects prompted an investigation of the role of $\mathrm{Ca}^{2+}$ in VP I I reproduction and stability.

Firstly, the effect of $\mathrm{Ca}^{2+}$ concentration on VP I I e.o.p. was determined by plating suitable dilutions of a lysate on nutrient agar plates containing a range of $\mathrm{Ca}\left(\mathrm{NO}_{3}\right)_{2}$ concentrations. Results showed that there was little difference in VP I I e.o.p. over the range I to Io mM. In 
Table 2. Analysis of crosses between two ts mutants of VP I I (II/I and II/3)

\begin{tabular}{|c|c|c|c|c|c|c|c|c|c|}
\hline \multirow[b]{3}{*}{ Cross } & \multirow{3}{*}{$\begin{array}{l}\text { Multi- } \\
\text { plicities } \\
\text { of each } \\
\text { parent }\end{array}$} & \multicolumn{2}{|c|}{$\begin{array}{l}\text { Proportion of } t s^{+} \text {in } \\
\text { reversion controls }\end{array}$} & \multirow{3}{*}{$\begin{array}{c}\text { Infected } \\
\text { centres/ } \\
\mathrm{ml} \\
(a)\end{array}$} & \multicolumn{2}{|c|}{$\begin{array}{l}\text { Final plating } \\
\text { (p.f.u./ml) }\end{array}$} & \multirow{3}{*}{$\begin{array}{l}\text { Relative } \\
\text { e.o.p. } \\
\text { at } 36{ }^{\circ} \mathrm{C} \\
(d)\end{array}$} & \multirow{3}{*}{$\begin{array}{c}\text { Average } \\
\text { burst } \\
\text { size } \\
(b / a)\end{array}$} & \multirow{3}{*}{$\begin{array}{c}\% w t \\
\text { recom- } \\
\text { binants } \\
(c / b d)\end{array}$} \\
\hline & & & & & $28^{\circ}$ & $36^{\circ}$ & & & \\
\hline & & II $/ 1$ & $11 / 3$ & & (b) & $(c)$ & & & \\
\hline I & $I \cdot 4+I \cdot 4$ & $4.0 \times 10^{-6}$ & $6.0 \times 10^{-5}$ & $2.4 \times 10^{6}$ & $4.0 \times 10^{7}$ & $5.0 \times 10^{5}$ & 0.70 & I 7 & $I \cdot 8$ \\
\hline 2 & $2+2$ & $\mathrm{I} \cdot 8 \times 10^{-5}$ & $3.0 \times 10^{-4}$ & $4.5 \times 10^{6}$ & $2.5 \times 10^{8}$ & $1.0 \times 10^{7}$ & 0.67 & 55 & $6 \cdot 0$ \\
\hline 3 & $2+2$ & $6.0 \times 10^{-6}$ & $1.4 \times 10^{-4}$ & $6.6 \times 10^{6}$ & $2.8 \times 10^{8}$ & $1.2 \times 10^{7}$ & 0.67 & 43 & $6 \cdot 3$ \\
\hline 4 & $2+2$ & $3.0 \times 10^{-6}$ & $\mathrm{I} \cdot \mathrm{O} \times 1 \mathrm{IO}^{-5}$ & $\mathrm{I} \cdot 1 \times 10^{7}$ & $4.7 \times 10^{8}$ & $1.7 \times 10^{7}$ & 0.67 & 43 & $5 \cdot 6$ \\
\hline 5 & $3+3$ & $6.3 \times 10^{-6}$ & $2 \cdot 2 \times 10^{-4}$ & $3.6 \times 10^{6}$ & $1.6 \times 10^{8}$ & $6.0 \times 10^{6}$ & 0.67 & 44 & $5 \cdot 6$ \\
\hline 6 & $5 \cdot 8+5 \cdot 8$ & $2.0 \times 10^{-6}$ & $5.0 \times 10^{-4}$ & $2.65 \times 10^{6}$ & $1.3 \times 10^{8}$ & $2.5 \times 10^{6}$ & 0.37 & 49 & $5 \cdot 2$ \\
\hline
\end{tabular}

the absence of added $\mathrm{Ca}^{2+}$, e.o.p. averaged 0.3 ; in the presence of an excess ( $100 \mathrm{~mm}$ ), e.o.p. was 0.005 .

Secondly, the effect of $\mathrm{Ca}^{2+}$ on survival of VP I I in liquid medium was tested. Flasks containing nutrient broth with and without added $\mathrm{Ca}\left(\mathrm{NO}_{3}\right)_{2}$ were inoculated with a VP I I lysate and incubated at $30{ }^{\circ} \mathrm{C}$ with shaking. Survival under these conditions was found to be markedly enhanced by the presence of $4 \mathrm{mM}^{-\mathrm{Ca}^{2+}}$. After $8 \mathrm{~h}$ of incubation, titres did not fall measurably in those flasks containing $\mathrm{Ca}^{2+}$; in the absence of added $\mathrm{Ca}^{2+}$ survival after $8 \mathrm{~h}$ varied between $10 \%$ and $30 \%$ in different experiments.

Thirdly, experiments to test a $\mathrm{Ca}^{2+}$ requirement for adsorption demonstrated that while calcium was not essential it did increase the rate of adsorption.

The finding that $\mathrm{Ca}^{2+}$ promoted the stability of VP I I in liquid led to the testing of various chelating agents and buffers as diluents. Portions of a lysate were diluted tenfold in various liquid media, stored at $4{ }^{\circ} \mathrm{C}$ for $\mathrm{I} \mathrm{h}$ and then diluted in broth and plated. Survival was better than $90 \%$ in nutrient broth, $0.2 \%$ peptone, distilled water and $4 \mathrm{~mm}-\mathrm{Ca}\left(\mathrm{NO}_{3}\right)_{2}$ solution. In Io mM-sodium citrate, phosphate-buffered saline and phage buffer (Glover, I962) irreversible inactivation occurred rapidly.

Genetic studies with VP II. Lysates of VP I I were subjected to three different mutagenic treatments. Plaques from platings showing between $\mathrm{IO}^{-2}$ and $\mathrm{IO}^{-3}$ survival were replicapicked with sterile toothpicks to pairs of plates overlaid with A3(2). One of each pair of plates was incubated at $28{ }^{\circ} \mathrm{C}$, the other at $36^{\circ} \mathrm{C}\left( \pm 0.5{ }^{\circ} \mathrm{C}\right)$ in an attempt to identify temperature-sensitive $(t s)$ mutants.

Two of the treatments, hydroxylamine at a range of concentrations and $365 \mathrm{~nm}$ u.v. light in the presence of $100 \mu \mathrm{g}$ of 8-methoxypsoralen $/ \mathrm{ml}$, caused considerable inactivation of the free phage particles with little or no mutagenesis.

The intracellular NG mutagenesis described under Methods, however, proved very successful. The survivors from many experiments were found to contain, on average, $2 \%$ plaque-morphology mutants. About 8 to $14 \%$ of the survivors were temperature-sensitive to some extent although many of these were too leaky to use.

Two reasonably non-leaky $t s$ mutants of VP II (II/I and II/3) were chosen for further study. Complementation between these two strains was demonstrated by means of a spot test (Edgar, Denhardt \& Epstein, 1964) and they were then tested for their ability to undergo recombination.

The proportion of wild-type ( $w t$ ) recombinants among the progeny was determined by comparing counts from plates incubated at 28 and $36^{\circ} \mathrm{C}$ after multiplying by the various dilution factors. The e.o.p. of VP I I $w t$ was found to be slightly lower $(0.3$ to 0.7$)$ at $36{ }^{\circ} \mathrm{C}$ than at $28^{\circ} \mathrm{C}$; a constant check on the difference was kept by incubating duplicate platings 


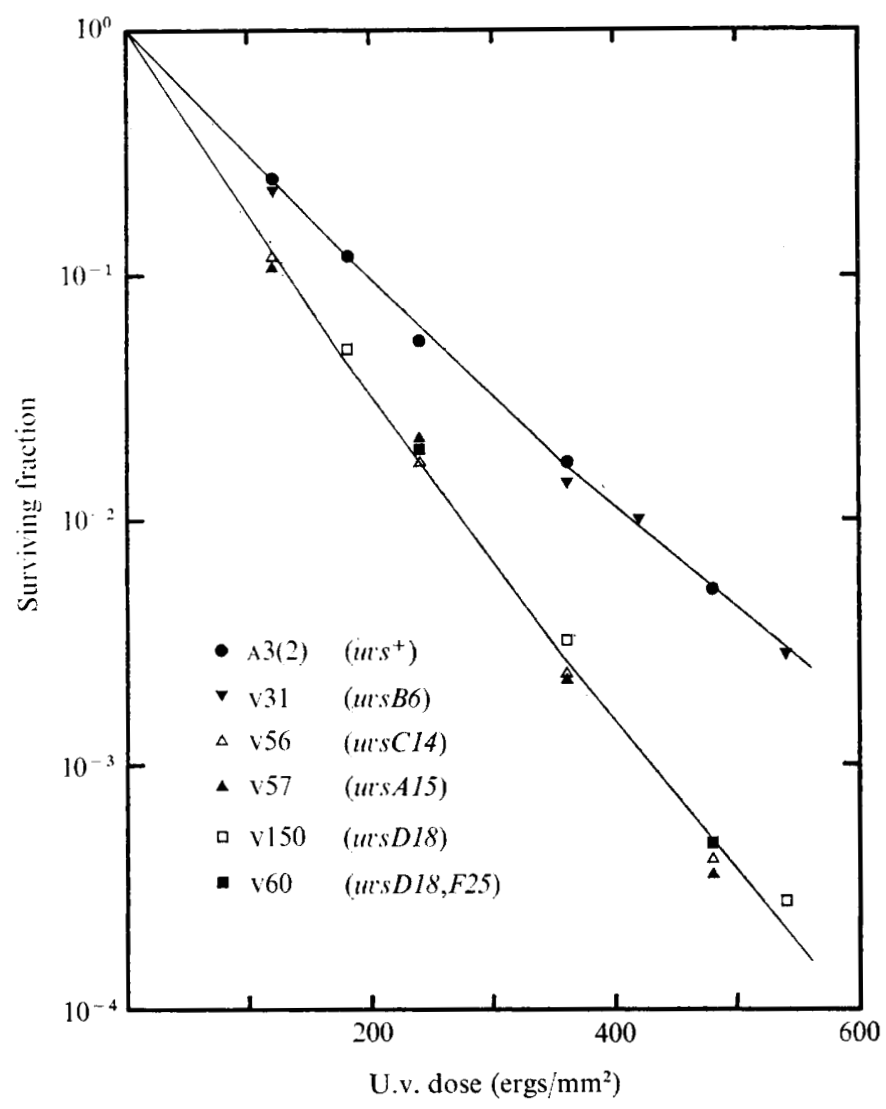

Fig. 6. U.v.-survival curves of VP I I plated on various $u v s$ strains and on $\mathrm{A3}(2)\left(u v s^{+}\right)$. Each point is the average of two experiments in the case of uvs strains and of eight experiments in the case of $\mathrm{A} 3(2)$.

of the $w t$ at the two temperatures and then multiplying any $36{ }^{\circ} \mathrm{C}$ counts by the appropriate factor.

Reversion controls were also performed on both the parents in the cross. Lysates of II/I prepared from single plaques usually contained revertants at a frequency of about $2 \times 10^{-6}$; for $I I / 3$ this value was usually about $10^{-4}$. Each strain was tested separately under the conditions of the cross and the proportions of $w t$ plaques were compared before and after. No detectable increase in the proportion of $w t$ plaques was found for either strain and it was concluded that there was no selection against $t s$ phages at the permissive temperature.

The data from the crosses are shown in Table 2. The results indicate a reproducible value of 5 to $6 \% w t$ recombinants. The value of the average burst size in each cross is shown for two reasons. Firstly it provides evidence that the cross is a satisfactory one (Edgar, 1963), and secondly the values shown are in reasonably good agreement with the value of 30 to 35 obtained in the one-step growth experiment.

U.v. irradiation studies. Fig. 6 shows the survival curves of VP I I on A3(2) and on some of the ultraviolet-sensitive (uvs) mutants isolated by Harold \& Hopwood (I970a, b). These survival curves demonstrate a moderate, but definite, host-cell reactivation (HCR) effect in A3(2). This appears to be the first report of HCR in a streptomycete. 
The finding that strains carrying mutations in the loci $u v s A, u v s C$ and $u v s D$ give very similar levels of VP II survival provides additional evidence that these loci determine parts of the same repair system (see Harold \& Hopwood, I970 $a, b$ ). VP I I survival on a $u v s B$ strain was essentially the same as on A3(2). Fig. 6 also shows that VP I I survival on strains VI50 (uvs DI8) and v60 (uvsDI8, F25) is very similar. In the host the uvsF25 mutation results in a dramatic decrease in survival in the absence of the wild-type $u v S A C D$ repair system.

The finding that survival on a strain carrying a $u v s B$ mutation ( $v_{3} 1$ ) is essentially the same as on the wild-type $\mathrm{A}_{3}(2)$ and that survival on a strain carrying a $u v s D$ mutation is unaffected by the uvs 25 mutation (vi 50 compared with v60) indicates that whatever systems are defined by $u v s B$ and $u v s F$ are apparently unable to repair u.v. damage to VP II.

\section{DISCUSSION}

A group of 28 phages acting on Streptomyces coelicolor A3(2) has been isolated, most of them by a technique of specific enrichment. Overnight incubation of enrichment flasks was found to be adequate and the negative results of Welsch, Rutten-Pinckaers \& Selman (1963) and Collard (1970), who incubated for 5 to 7 days, may well have been due to re-adsorption of phages to dead or old, non-productive stationary-phase hyphae. The explanation offered by Collard (1970) for her failure to isolate $\mathrm{A} 3$ (2)-specific phages was that the host produced an antiphage substance. This seems unlikely considering the ease with which phages were isolated in the present study.

It has often been noted that many actinophages are able to attack a very wide range of streptomycetes (e.g. Carvajal, 1955; Bradley, Anderson \& Jones, 196I). In one case (Bradley \& Anderson, I958) it was reported that several phages were capable of lysing members of both the genera Streptomyces and Nocardia. An apparently wide host-range may, of course, result from incorrect classification (including unnecessary speciation) of the host strains. Many of the features used in grouping streptomycetes have been combined into one classification by Hütter (1967). In this system, strains are differentiated by four criteria: spore morphology (smooth/warty, hairy or spiny), colour of aerial growth (six groups based on those of Tresner \& Backus, I 963), morphology of aerial growth (six groups based on those of Pridham, Hesseltine \& Benedict, 1958) and the ability to produce melanin on peptonecontaining nutrient medium.

VP I I was found to attack members of all three spore-morphology groups, all six colour groups and both melanin-producing and non-producing strains. Only four of the six aerial growth morphology groups were represented in the strains tested and members of all these were also lysed by VP II. Thus by any of the commonly used systems of Streptomyces classification VP I I has a remarkably wide host-range.

There is little remarkable about the morphology or dimensions of VP II. In many micrographs of preparations stained with potassium phosphotungstate (including Fig. I) a high proportion of the particles were found to be ghosts or to have separated into heads and tails. VP II is known to be sensitive to chelating agents and the damage observed may well have been due, at least in part, to the sequestration of $\mathrm{Ca}^{2+}$ by the phosphotungstate. Such phosphotungstate-induced damage has been reported for the Bacillus stearothermophilus phage TP 84 (Bassel, Shaw \& Campbell, 1971).

It is generally agreed that old Streptomyces mycelium will not support phage growth (Van Alstyne, Otto \& McCoy, I955; Welsch,' 1956 ). In the experiments described here phage e.o.p. was consistently lower when mycelium was the host inoculum but the differences were often small, especially in the case of $\mathrm{A} 3(2)$. The probable explanation for this is that old 
mycelium incubated in a top layer will begin to grow (probably within a few hours) and the new growth, which is physiologically young, will support phage replication effectively. The lower e.o.p. probably results from the loss of that fraction of the phage population which is adsorbed to old mycelium before much growth has occurred.

The attachment experiments described were designed to measure total adsorption and no attempt was made to desorb any reversibly adsorbed particles. The adsorption rate constants calculated show, on the face of it, that adsorption is more efficient to old substrate mycelium than it is to newly germinated spores. These values, however, were calculated by using initial host concentrations and are probably meaningless; on spore germination the effective target for phages will be increased many-fold as a young mycelial network begins to form around each spore. Real adsorption is thus much less rapid than it appears to be from the constants. To what extent old mycelium increases under these conditions is unknown. Thus it is impossible to say whether adsorption is more efficient to young or to old mycelium and it is difficult to compare adsorption rates of Streptomyces phages with other systems. It seems very likely, however, from the argument above that the constants calculated are gross overestimates.

The value of $40 \mathrm{~min}$ for the latent period of VP I I (which is apparently short for an actinophage - Welsch, 1969) was confirmed in many adsorption experiments. In the few Streptomyces phage systems where independent work has been carried out, burst sizes seem to be very variable and not reproducible. The probable explanation is suggested by the observation of Ritzi, Bradley \& Jones (1968) that the burst size increases as host germlings get older. As newly germinated spores produce hyphae, these grow round one another and clumping occurs. When spores have just germinated, clumping is at a minimum and burst sizes should be reasonably accurate. After some time, however, large clumps form which will attach many phage particles although each clump will only plate as one infected centre. It will, of course, release many individual bursts and so the observed average burst size is artificially inflated.

Thus the observed burst size of VP I I is being affected by at least two experimental factors. Clumping of host growth may be inflating the burst size while the fact that infected centres have a higher e.o.p. than do free phage will be reducing it. Evidence for the higher e.o.p. of infected centres was provided by the finding (Dowding, 1972) that the total yield of plaques rose by a factor of about two when pre-adsorption for 30 min to germinated spores was allowed before assaying in top layers in the usual way.

The results of the crosses (Table 2) show that there is no significant change in the number of recombinants produced at initial total multiplicities of 4,6 or I I 6 . More recombinants would be expected at the higher multiplicity and the fact that the proportion of recombinants does not increase suggests that the initial multiplicities were higher than they appeared to be. The manner in which a cross is performed makes this likely. In order to avoid excessive clumping of young mycelium, which would lead to inaccuracies in burst-size determination, spore suspensions were used at an early stage of germination. A considerable proportion of the spores would not have begun to germinate by the time the cross was performed and thus the number of cells (effective target for the phage) was smaller and the real multiplicity was higher.

From its size, the fact that it is host-cell reactivated and the fact that mutants of it undergo genetic recombination, it seems very likely that VP I I contains double-stranded DNA as its nucleic acid.

A common belief seems to persist that 'actinophages' are somehow basically different from 'bacteriophages'. All the experiments reported here reveal VP II to be a typical bac- 
teriophage, differing only in the complex, mycelial nature of its host. At the present time this mycelial nature makes streptomycetes less than ideal for quantitative studies with phages. Many strains, including A3(2), do not germinate synchronously with the result that by the time a high enough proportion of the spores have germinated, some of them will be large clumps of mycelium. These clumps can adsorb a great many phage particles yet continue to plate as single colony-forming units. The concept of multiplicity of infection will thus remain meaningless in this system until a means is found of causing synchronous and uniform spore germination.

The demonstration of a workable phage system in Streptomyces coelicolor A3(2) has made available many new technical approaches to the study of this organism that are in common use in other bacteria. In particular, VP I I has already aided analysis of some uvs mutants, and it and other phages are currently being used in a biochemical investigation of differentiation (see Chater \& Hopwood, 1973) and in a search for nonsense suppressors in A3(2) (V. Najfeld, personal communication).

It is a pleasure to thank Professor D. A. Hopwood for his continued help and advice and for discussing the manuscript. I also thank Guy C. Higby for excellent assistance with many of the experiments reported here. Thanks are also due to Dr T. Cross of the University of Bradford for supplying bacterial cultures. I am grateful to the Directors of Pfizer Ltd for financial support.

\section{REFERENCES}

ADAMS, M. H. (1959). Bacteriophages. New York: Wiley-Interscience.

Bassel, A., Shaw, M. \& Campbell, L. L. (197I). Dissociation by chelating agents and substructure of the thermophilic bacteriophage TP 84. Journal of Virology 7, 663-672.

BradLEY, D. E. (1967). Ultrastructure of bacteriophages and bacteriocins. Bacteriological Reviews 31, 230314.

Bradley, S. G. \& Anderson, D. L. (1958). Taxonomic implication of actinophage host-range. Science, New York 128, 413-4I4.

Bradley, S. G., Anderson, D. L. \& Jones, L. A. (196I). Phylogeny of Actinomycetes as revealed by susceptibility to actinophage. Developments in Industrial Microbiology 2, 223-237.

Carvajal, F. (I955). Host-parasite relations with a polyvalent streptomycophage from Streptomyces griseus. Antibiotics and Chemotherapy 5, 28-32.

CHATER, K. F. (1972). A morphological and genetic mapping study of white colony mutants of Streptomyces coelicolor. Journal of General Microbiology 72, 9-28.

Chater, K. F. \& Hopwood, D. A. (1973). Differentiation in Actinomycetes. Symposium of the Society for General Microbiology 23, 143-I60.

Collard, C. A. (1970). Étude comparative des méthodes d'isolement d'actinophages à partir de leurs habitats naturels. Comptes rendues des séances de la Société de Biologie 164, 465-468.

Dowding, J. E. (1972). Studies on bacteriophages of Streptomyces coelicolor. Ph.D. Thesis, University of East Anglia, Norwich.

EdGAR, R. S. (I963). Some technical considerations concerning experiments on phage recombination. In Methodology in Basic Genetics, pp. 19-36. Edited by W. J. Burdette. San Francisco: Holden Day.

Edgar, R. S., Denhardt, G. H. \& Epstein, R. H. (1964). A comparative genetic study of conditional lethal mutations of bacteriophage $\mathrm{T}_{4} \mathrm{D}$. Genetics $49,635-648$.

Glover, S. W. (1962). Valine-resistant mutants of Escherichia coli K-12. Genetical Research 3, 448-460.

HaRold, R. J. \& Hopwood, D. A. (1970a). Ultraviolet-sensitive mutants of Streptomyces coelicolor. I. Phenotypic characterisation. Mutation Research ro, 427-438.

HAROLD, R. J. \& HoPwood, D. A. (I970 b). Ultraviolet-sensitive mutants of Streptomyces coelicolor. II. Genetics. Mutation Research ro, 439-448.

Hopwood, D. A. (1967). Genetic analysis and genome structure in Streptomyces coelicolor. Bacteriological Reviews 3r, 373-403. 
Hopwood, D. A. \& Sermonti, G. (1962). The genetics of Streptomyces coelicolor. Advances in Genetics $\mathbf{I r}$, 273-342.

Hopwood, D. A., Wildermuth, H. \& Palmer, H. M. (1970). Mutants of Streptomyces coelicolor defective in sporulation. Journal of General Microbiology 6r, 397-408.

HütTER, R. (1967). Systematik der Streptomyceten. Basel: Karger-Verlag.

KutZner, H. J. \& WAKSMAN, S. A. (1959). Streptomyces coelicolor Müller and Streptomyces violaceoruber Waksman and Curtis, two distinctly different organisms. Journal of Bacteriology 78, 528-538.

Lomovskaya, N. D., Emeljanova, L. K. \& Alikhanian, S. I. (I97I). The genetic location of prophage on the chromosome of Streptomyces coelicolor. Genetics 68, 34 I-347.

Lomovskaya, N. D., Mkrtumian, N. M., Gostimskaya, N. L. \& Danilenko, V. N. (i972). Characterization of temperate actinophage $\varnothing \mathrm{C}_{3}$ I isolated from Streptomyces coelicolor $\mathrm{A}_{3}(2)$. Journal of Virology 9, $258-262$.

Pridham, T. G., Hesseltine, C. W. \& Benedict, R. G. (I958). A guide for the classification of streptomycetes according to selected groups. Placement of strains in morphological sections. Applied Microbiology 6, $52-79$.

Ritzi, D., Bradley, S. G. \& Jones, L. A. (i968). Ultrastructure of phage-infected Streptomyces venezuelae. Developments in Industrial Microbiology 9, 235-241.

Studier, F. W. (1969). The genetics and physiology of bacteriophage T 7. Virology 39, 562-574.

Tresner, H. D. \& Backus, E. J. (I963). System of color wheels for streptomycete taxonomy. Applied Microbiology II, 335-338.

Van Alstyne, M. H., Otto, R. H. \& McCoy, E. (1955). Characteristics of Streptomyces griseus strains resistant to phage. Journal of Bacteriology 70, I13-1 I9.

Vivian, A. (I97I). Genetic control of fertility in Streptomyces coelicolor A3(2): plasmid involvement in the interconversion of UF and IF strains. Journal of General Microbiology 69, 353-364.

WelsCh, M. (I956). Influence de l'âge d'un Streptomyces sur ses réactions à un actinophage. Comptes rendues des séances de la Société de Biologie 150,609-613.

Welsch, M. (1969). Biology of actinophages. Symposium on Genetics and Breeding of Streptomyces, Dubrovnik, pp. 43-62. Zagreb: Yugoslav Academy of Sciences and Arts.

Welsch, M., Minon, A. \& Schönfeld, J. K. (I955). Isolation of actinophages. Experientia II, 24-25.

Welsch, M., Rutten-Pinckaers, A. \& Selman, M. (1963). Recherches sur des Streptomyces d'Afrique Centrale. IV. Isoantibiose, lysogénie et actinophages. Bulletin de la Société royale des sciences de Liège 32, 529-573.

Wieringa, K. T. \& Wiebols, G. L. W. (I936). De aardappelschurft en de heterolyse des schurftparasiet. Tijdschrift over Plantenziekten 42, 235-240. 